\title{
Successful Treatment of Spontaneous Coronary Artery Dissection With Cutting Balloon Angioplasty
}

\author{
Mohamed Zghouzi ${ }^{1}$, Homam Moussa Pacha ${ }^{2}$, Yasar Sattar ${ }^{3}$, M. Chadi Alraies ${ }^{4}$
}

1. Internal Medicine, Detroit Medical Center, Detroit, USA 2. Cardiovascular Disease, University of Texas Health Science Center at Houston McGovern Medical School, Houston, USA 3. Internal Medicine, Icahn School of Medicine at Mount Sinai, New York, USA 4. Cardiology, Detroit Medical Center, Detroit, USA

Corresponding author: Mohamed Zghouzi,m.zghouzi@gmail.com

\begin{abstract}
Spontaneous coronary artery dissection (SCAD) is a rare but serious condition that requires immediate attention. It has a similar presentation to acute coronary syndrome in terms of chest pain, electrocardiogram changes, and an increase in troponins, and is considered to be a significant cause of myocardial infarction. Coronary angiography is needed to confirm the diagnosis, and subsequent repair should be pursued when needed. We describe a case of SCAD in a 72-year-old female treated using the cutting balloon angioplasty technique to create communication between the true and false lumens.
\end{abstract}

Categories: Cardiology

Keywords: spontaneous coronary artery dissection, scad, cutting balloon, endovascular angioplasty

\section{Introduction}

Spontaneous coronary artery dissection (SCAD) is a rare but serious condition that requires immediate attention. SCAD is an uncommon and underdiagnosed condition. It is a condition of a younger patient group and predominant in women $[1,2]$. It has a similar presentation to acute coronary syndrome (ACS) in terms of chest pain, electrocardiogram changes, and an increase in troponins, and is considered to be a significant cause of myocardial infarction. Coronary angiography is needed to confirm the diagnosis, and subsequent repair should be pursued when needed. The estimated prevalence of SCAD in patients presenting with ACS ranges from 1.7 to $4 \%[3,4]$, and in women younger than 50 years of age and presenting with ACS, it ranges from 9 to $43 \%$ [4-6]. Once the diagnosis is confirmed, management is often determined by the angiographic patency of the coronary artery. Options for therapy include conservative management with no intervention, coronary angioplasty, or coronary stenting. However, coronary imaging could establish the diagnosis and etiology. Therefore, the current recommendation is to refrain from coronary stenting, especially if the coronary flow is preserved. In this case, we present a patient with ACS who was found with coronary dissection and treated with cutting balloon angioplasty alone. To confirm the patency of the coronary artery, computed tomography angiogram was done a few weeks later, which showed patency of the vessel.

Review began 02/23/2021 Review ended 03/01/2021 Published 03/04/2021

\section{() Copyright 2021}

Zghouzi et al. This is an open access article distributed under the terms of the Creative Commons Attribution License CC-BY 4.0., which permits unrestricted use, distribution, and reproduction in any medium, provided the original author and source are credited.

\section{Case Presentation}

A 72-year-old female with a medical history of hypertension, paroxysmal atrial fibrillation, type B thoracic aortic dissection status, post-percutaneous endovascular repair, stenting gastroepiploic artery aneurysm status post coil embolization, and mitral valve prolapse presented with chest pain. She described the chest pain as heavy and centrally located. The chest pain had progressed in severity by the time she was seen in the emergency department. ECG showed diffuse ST-segment elevation (Figure 1).

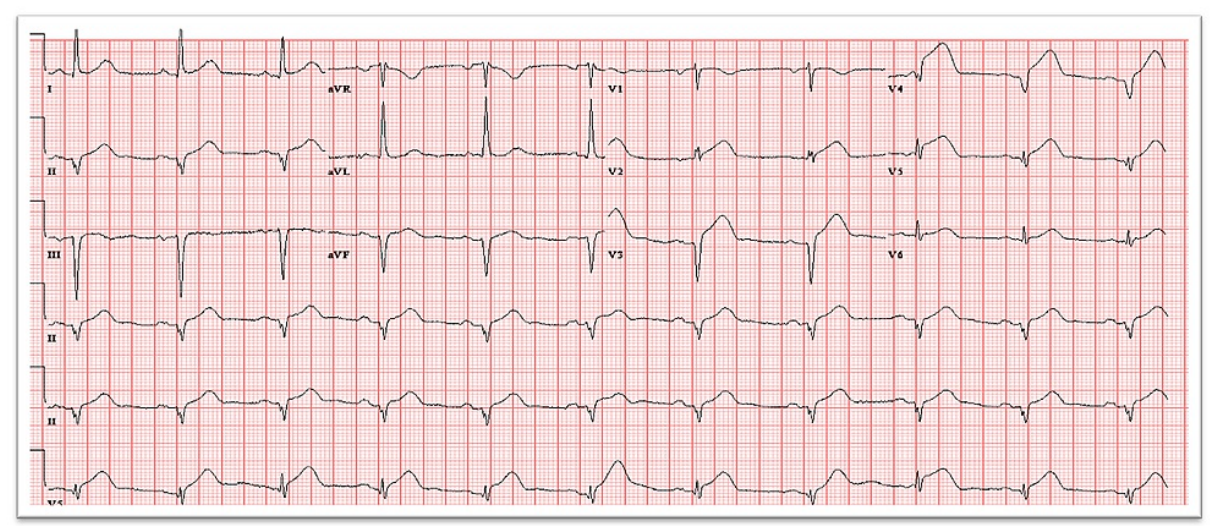




\section{Cureus}

FIGURE 1: ECG showing diffuse ST-segment elevation in leads V1-V5.

ECG, electrocardiogram

Bedside ECG was performed, showing an ejection fraction of $25 \%$, severely hypokinetic anterior wall, and an akinetic apical septum, apex, and inferior wall. Laboratory investigation demonstrated a troponin level of 1 $\mathrm{ng} / \mathrm{mL}$.

The patient was taken emergently to the cardiac catheterization laboratory. Radial access and a 5-Fr tiger catheter were used. Complete occlusion of the mid-section of the left anterior descending (LAD) artery and Thrombolysis in Myocardial Infarction (TIMI) flow score of 0-1 due to spontaneous coronary artery dissection (Figure $2 A$ ) were noted. A 0.014-Fr Fielder XT coronary guidewire was advanced across the dissection planes, and the mid-LAD high-grade stenosis was achieved without difficulty. Although the initial plan was to stent the mid-LAD stenotic segment, as the lesion was not atherosclerotic, a decision to perform atherectomy balloon angioplasty of the segment using the $3.0 \times 20 \mathrm{~mm}$ "cutting balloon" was made (Boston Scientific, Marlborough, MA, USA) (Figure 2B). Cutting balloon angioplasty created communication between the true and false lumens and restored the distal coronary flow (Figure 2C).
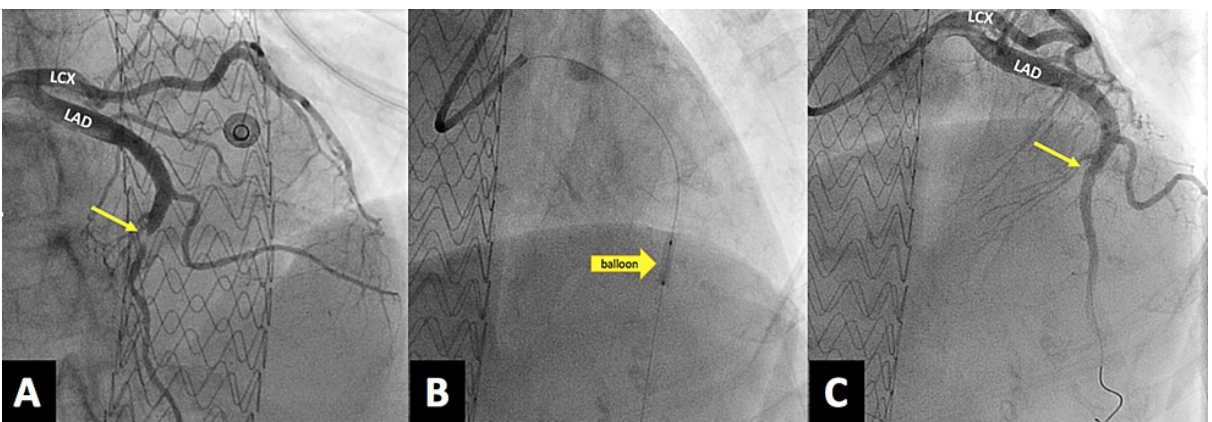

FIGURE 2: (A) Complete occlusion of the mid-section of the LAD artery and a TIMI flow score of 0-1 due to SCAD (arrow). (B) Coronary angiography showing $2.5-\mathrm{mm}$ cutting balloon dilated in the proximal and distal segments of LAD artery (arrow). (C) Coronary angiography showing coronary flow restored to TIMI flow 3 after ballooning (arrow).

LAD, left anterior descending; TIMI, Thrombolysis in Myocardial Infarction; SCAD, spontaneous coronary artery dissection

After the procedure, the TIMI flow score was restored to 3 . The procedure was uncomplicated, and the patient was discharged in good condition on warfarin and clopidogrel, given her history of paroxysmal atrial fibrillation.

A four-week follow-up coronary computed tomography was performed, showing a normal course and caliber of the LAD artery giving rise to two diagonal branches. Furthermore, the vessel was fully opacified throughout without luminal narrowing, stenosis, or evidence of dissection (Figure 3). 


\section{Cureus}

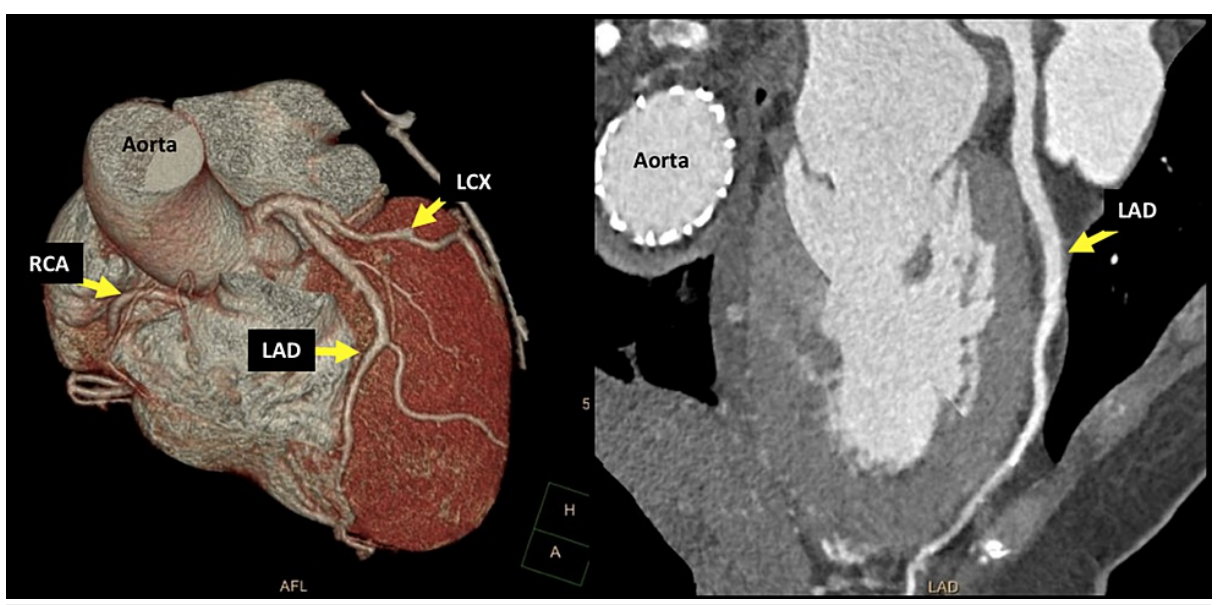

FIGURE 3: CTA showing ordinary course and caliber of LAD artery fully opacified without luminal narrowing or stenosis or evidence of dissection.

CTA, computed tomography angiography; LAD, left anterior descending; LCX, left circumflex artery; RCA, right coronary artery

\section{Discussion}

SCAD is defined as a spontaneous separation of the coronary artery wall that is not iatrogenic or related to trauma [2]. The first reported case of SCAD was in 1931 in middle-aged women.

Usually, patients present with an ACS spectrum such as unstable angina, non-ST elevation myocardial infarction, ST-elevation myocardial infarction, or sudden cardiac death [1]. The etiology is nonatherosclerotic and associated with clinical features such as fibromuscular dysplasia, pregnancy or postpartum state, connective tissue disorders, systemic inflammatory disease, and coronary artery spasm. Precipitators usually include exertion or emotional stress [1,2]. Many SCAD patients have a low pretest probability of coronary artery disease, potentially missing the diagnosis or delayed intervention.

Coronary angiography is the golden standard for diagnosing SCAD. Furthermore, intracoronary imaging made the diagnosis of SCAD easy in patients presenting with ACS. This condition is usually sub-categorized into three types: type 1 (contrast staining delineating multiple lumens), type 2 (diffuse smooth narrowing), and type 3 (similar to atherosclerosis), with type 2 being the most common. The use of intracoronary in the form of optical coherence tomography and intravascular ultrasound can help diagnose type 2 and type 3 ACS $[2,7]$.

The management of acute SCAD depends on the affected vessel's distal flow, clinical, and hemodynamic stability. Percutaneous coronary intervention (PCI) is often challenging and is associated with a high failure rate, even when distal coronary perfusion is preserved [8]. Medical management is reserved for clinically stable patients with a good distal coronary flow (TIMI score: 2-3) [8]. When hemodynamic stability is not achieved or in the case of failed medical management, PCI or coronary artery bypass grafting is indicated. There are several cases reported in the literature where scoring/cutting balloon angioplasty is used to treat SCAD, either as an initial treatment or when stenting failed to restore flow to the affected artery (Table 1).

There are scant data concerning the ideal medical therapy for acute SCAD. Aspirin is given to most patients, regardless of their atherosclerotic disease status. Clopidogrel and heparin are reserved for clinically appropriate situations. Beta-blockers play an important role in reducing arterial shear stress and ventricular arrhythmia and improving survival $[2,9]$. Angiotensin-converting enzyme inhibitors treatment is reserved for patients with left ventricular dysfunction. Treatment with nitrates or calcium channel blockers is reasonable in the presence of chest pain, which is likely related to dissection or coronary spasm.

Long-term survival in acute SCAD settings is excellent, but the risk of recurrence and myocardial infarction is high in this patient population. [1] Daily low-dose aspirin is recommended for all patients, but dual antiplatelet therapy is reserved for patients with PCI. 


\section{Cureus}

\begin{tabular}{|c|c|c|c|c|c|c|}
\hline Author & Year & Age & Sex & Location & Treatment & Imaging follow-up \\
\hline Terzian et al. [10] & 2019 & 34 & $\mathrm{~F}$ & LAD & Scoring balloon angioplasty & $\begin{array}{l}\text { Coronary angiogram at } 9 \\
\text { months }\end{array}$ \\
\hline Kaya et al. [11] & 2019 & 46 & $\mathrm{~F}$ & LAD & Cutting balloon angioplasty & $\begin{array}{l}\text { Coronary CTA at } 1 \text { and } 6 \\
\text { months }\end{array}$ \\
\hline $\begin{array}{l}\text { Sharma et al. } \\
\text { [12] }\end{array}$ & 2019 & 53 & $\mathrm{~F}$ & RCA & Cutting balloon angioplasty & NA \\
\hline Main et al. [13] & 2019 & 62 & $\mathrm{~F}$ & $\begin{array}{l}\text { Large diagonal } \\
\text { branch }\end{array}$ & Cutting balloon angioplasty & ECG in 6 weeks \\
\hline $\begin{array}{l}\text { Bresson et al. } \\
\text { [14] }\end{array}$ & 2019 & 36 & $\mathrm{~F}$ & Proximal LAD & $\begin{array}{l}\text { Stenting and cutting balloon } \\
\text { angioplasty }\end{array}$ & NA \\
\hline $\begin{array}{l}\text { McGrath et al. } \\
\text { [15] }\end{array}$ & 2018 & 51 & $\mathrm{~F}$ & LM, LAD, LCX & $\begin{array}{l}\text { Stenting and cutting balloon } \\
\text { angioplasty }\end{array}$ & NA \\
\hline $\begin{array}{l}\text { Noguchi et al. } \\
{[16]}\end{array}$ & 2018 & 42 & M & LAD, LCX & $\begin{array}{l}\text { Cutting balloon angioplasty and } \\
\text { stenting }\end{array}$ & $\begin{array}{l}\text { Coronary angiogram at } 6 \\
\text { months }\end{array}$ \\
\hline Ito et al. [17] & 2017 & 46 & $\mathrm{~F}$ & LAD & Cutting balloon angioplasty & Coronary CTA at 3 months \\
\hline $\begin{array}{l}\text { Alkhouli et al. } \\
\text { [18] }\end{array}$ & 2016 & 50 & $\mathrm{~F}$ & LAD & $\begin{array}{l}\text { Cutting balloon angioplasty and } \\
\text { stenting }\end{array}$ & NA \\
\hline $\begin{array}{l}\text { Yumoto et al. } \\
\text { [19] }\end{array}$ & 2014 & 47 & $\mathrm{~F}$ & LAD & Cutting balloon angioplasty & $\begin{array}{l}\text { Coronary angiogram at } 6 \\
\text { months }\end{array}$ \\
\hline Uema et al. [20] & 2013 & 42 & $\mathrm{~F}$ & LAD & Cutting balloon angioplasty & NA \\
\hline
\end{tabular}

TABLE 1: Previous case reports in the literature describing cutting/scoring balloon angioplasty in SCAD treatment.

LAD, left anterior descending; CTA, computed tomography angiography; RCA, right coronary artery; ECG, electrocardiogram; LM, left main; LCX, left circumflex artery; SCAD, spontaneous coronary artery dissection

\section{Conclusions}

Balloon angioplasty using a cutting balloon for patients presenting with SCAD and TIMI score 0 flow can offer immediate and long-term flow patency of a coronary artery with no requirement for coronary stenting.

\section{Additional Information}

\section{Disclosures}

Human subjects: Consent was obtained or waived by all participants in this study. Conflicts of interest: In compliance with the ICMJE uniform disclosure form, all authors declare the following: Payment/services info: All authors have declared that no financial support was received from any organization for the submitted work. Financial relationships: All authors have declared that they have no financial relationships at present or within the previous three years with any organizations that might have an interest in the submitted work. Other relationships: All authors have declared that there are no other relationships or activities that could appear to have influenced the submitted work.

\section{References}

1. Tweet MS, Hayes SN, Pitta SR, et al.: Clinical features, management, and prognosis of spontaneous coronary artery dissection. Circulation. 2012, 126:579-588. 10.1161/CIRCULATIONAHA.112.105718

2. Saw J, Mancini GB, Humphries KH: Contemporary review on spontaneous coronary artery dissection. J Am Coll Cardiol. 2016, 68:297-312. 10.1016/j.jacc.2016.05.034

3. Nishiguchi T, Tanaka A, Ozaki Y, et al.: Prevalence of spontaneous coronary artery dissection in patients with acute coronary syndrome. Eur Heart J Acute Cardiovasc Care. 2016, 5:263-270. $10.1177 / 2048872613504310$

4. Rashid HN, Wong DT, Wijesekera $\mathrm{H}$, et al.: Incidence and characterisation of spontaneous coronary artery dissection as a cause of acute coronary syndrome--a single-centre Australian experience. Int J Cardiol. 2016, 202:336-338. 10.1016/j.ijcard.2015.09.072

5. Elkayam U, Jalnapurkar S, Barakkat MN, Khatri N, Kealey AJ, Mehra A, Roth A: Pregnancy-associated acute 
myocardial infarction: a review of contemporary experience in 150 cases between 2006 and 2011. Circulation. 2014, 129:1695-1702. 10.1161/CIRCULATIONAHA.113.002054

6. Nakashima T, Noguchi T, Haruta S, et al.: Prognostic impact of spontaneous coronary artery dissection in young female patients with acute myocardial infarction: a report from the Angina Pectoris-Myocardial Infarction Multicenter Investigators in Japan. Int J Cardiol. 2016, 207:341-348. 10.1016/j.ijcard.2016.01.188

7. Saw J: Coronary angiogram classification of spontaneous coronary artery dissection. Catheter Cardiovasc Interv. 2014, 84:1115-1122. 10.1002/ccd.25293

8. Tweet MS, Eleid MF, Best PJ, et al.: Spontaneous coronary artery dissection: revascularization versus conservative therapy. Circ Cardiovasc Interv. 2014, 7:777-786. 10.1161/CIRCINTERVENTIONS.114.001659

9. Amsterdam EA, Wenger NK, Brindis RG, et al.: 2014 AHA/ACC guideline for the management of patients with non-ST-elevation acute coronary syndromes: a report of the American College of Cardiology/American Heart Association Task Force on Practice Guidelines. J Am Coll Cardiol. 2014, 64:139-228. 10.1016/j.jacc.2014.09.017

10. Terzian Z, Demian H, Karrillon GJ, Aubry P: Fenestration of a spontaneous coronary hematoma with lifethreatening dissection: a case of recurrent and multivessel spontaneous coronary artery dissections in a young female [Article in French]. Ann Cardiol Angeiol (Paris). 2019, 68:382-388. 10.1016/j.ancard.2019.08.009

11. Kaya E, Iwata H, Miyazaki S, et al.: Successful coronary flow restoration by stent-free strategy using the pullback method of cutting balloon in spontaneous coronary artery dissection. CJC Open. 2019, 1:213-215. 10.1016/j.cjco.2019.05.008

12. Sharma H, Vetrugno V, Khan SQ: Successful treatment of a spontaneous right coronary artery dissection with a 4-mm diameter cutting balloon: a case report. Eur Heart J Case Rep. 2019, 3:1-6. 10.1093/ehjcr/ytz212

13. Main A, Lombardi WL, Saw J: Cutting balloon angioplasty for treatment of spontaneous coronary artery dissection: case report, literature review, and recommended technical approaches. Cardiovasc Diagn Ther. 2019, 9:50-54. 10.21037/cdt.2018.10.11

14. Bresson D, Calcaianu M, Lawson B, Jacquemin L: Coronary artery fenestration as rescue management of intramural haematoma with luminal compression. Catheter Cardiovasc Interv. 2019, 94:17-19. $10.1002 / \mathrm{ccd} .28186$

15. McGrath BM, Vo MN: Novel use of cutting balloon to manage compressive subintimal hematoma during left main stenting in a patient with spontaneous coronary artery dissection. Clin Case Rep. 2018, 6:1291-1295. $10.1002 / \mathrm{ccr} 3.1531$

16. Noguchi M, Obunai K, Fukui Y, Okumura H, Watanabe H: Usefulness of cutting balloon angioplasty prior to stenting with intravascular ultrasound imaging guidance for spontaneous multi-vessel coronary artery dissection including the left main coronary artery. Intern Med. 2018, 57:1867-1871. 10.2169/internalmedicine.0177-17

17. Ito T, Shintani Y, Ichihashi T, Fujita H, Ohte N: Non-atherosclerotic spontaneous coronary artery dissection revascularized by intravascular ultrasonography-guided fenestration with cutting balloon angioplasty. Cardiovasc Interv Ther. 2017, 32:241-243. 10.1007/s12928-016-0397-X

18. Alkhouli M, Cole M, Ling FS: Coronary artery fenestration prior to stenting in spontaneous coronary artery dissection. Catheter Cardiovasc Interv. 2016, 88:23-27. 10.1002/ccd.26161

19. Yumoto K, Sasaki H, Aoki H, Kato K: Successful treatment of spontaneous coronary artery dissection with cutting balloon angioplasty as evaluated with optical coherence tomography. JACC Cardiovasc Interv. 2014, 7:817-819. 10.1016/j.jcin.2013.10.027

20. Uema A, Araki M, Sonoda S, et al.: Successful coronary intervention for spontaneous coronary dissection in a patient with fibromuscular dysplasia. J Cardiol Cases. 2013, 8:158-160. 10.1016/j.jccase.2013.07.011 